\title{
Total Synthesis of the fungal metabolite Trienylfuranol A via Nucleophilic Diastereodivergent Additions to Oxocarbenium lons
}

\author{
Guillaume Arcile, Pascal Retailleau, Jamal Ouazzani and Jean-Francois Betzer*
}

\begin{tabular}{l}
\hline$\left.{ }^{\star}\right] \quad$ G. Arcile, P. Retailleau, Dr. J. Ouazzani, Dr. J.-F. Betzer \\
Institut de Chimie des Substances Naturelles, CNRS UPR 2301, Université Paris-Saclay \\
1 avenue de la Terrasse, 91198 Gif-sur-Yvette Cedex, France \\
E-mail: $\quad$ amal.ouazzani@cnrs.fr \\
\\
https://icsn.cnrs.fr/
\end{tabular}

Supporting information for this article is given via a link at the end of the document.

\begin{abstract}
Herein, we describe the first total synthesis of trienylfuranol $A$, a fungal triene-substituted tetrahydrofuran metabolite. The stereoselectivity of the chiral center bearing the trienyl side chain was diastereodivergently controlled by the addition of nucleophilic species on substituted $\gamma$-butyrolactone. Remarkably, the $C$-nucleophilic species or hydride addition onto oxocarbenium intermediate leads to the opposite diastereoselectivity reported for Kishi or Woerpel models. The use of Hantzsch ester ( $\mathrm{HEH})$ as organic hydride donor has enabled us to access to the desired stereochemistry. The total synthesis of trienylfuranol A was achieved in 8 steps from acetaldehyde and pyruvic acid.
\end{abstract}

We previously isolated the sporochartine family of natural compounds from the fungus Hypoxylon monticulosum CLL 205, ${ }^{[1]}$ now referred as Hypomontagnella spongiphila. ${ }^{[2]}$ According to the structure of the sporothriolide $1^{[3]}$ and the trienylfuranol A $2,{ }^{[4]}$ we suggested that sporochartines A-D 3a-d might derive from a Diels-Alder type reaction between 1 and 2 (Figure 1). The cultivation of Hypoxylon monticulosum CLL 205 offers significant quantity of $\mathbf{1}$ and $\mathbf{3 a - d}$, while $\mathbf{2}$ is only detected in very low amount. In the context of our ongoing research program on biosynthetic pathway of sporochartine 3a-d natural products and in order to elucidate the mechanism of reaction between 1 and 2 , we engaged the total synthesis of trienylfuranol A 2; sporothriolide 1 is easily isolated in gram-scale from the cultivation broth.

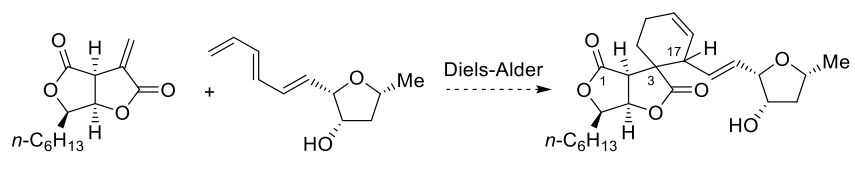

sporothriolide (1) trienylfuranol A (2) sporochartine A-D (3a-d)

Figure 1. Plausible biosynthetic pathway of sporochartines through Diels-Alder cycloaddition between sporothriolide and trienylfuranol $\mathrm{A}$.

In order to provide an efficient synthetic pathway of trienylfuranol A 2, and in respect to the stability of this natural metabolite which is highly susceptible to polymerization or degradation upon synthesis or purification, ${ }^{[4]}$ we considered to perform the synthesis involving two major milestones. First, we planned to synthetize a trisubstituted and functionalized furan $\mathbf{V}$, bearing the three stereogenic centers in all-cis-relationship, and secondly the introduction of the terminal trienic side chain (Scheme 1). The $\alpha$ - hydroxy- $\gamma$-butenolide I can be smoothly hydrogenated over palladium to produce the disubstituted- $\gamma$-butyrolactone II as a single diastereoisomer. This lactone II should be converted into cis-trisubstituted furan $\mathbf{V}$. This will be achieved through the introduction of a functionalized side chain followed by a reduction at the same site, operations that can be performed in any order. The last substitution stage, which involves the formation of oxocarbenium intermediate, set up the C-2 stereogenic center. Even if stereoselective addition of nucleophilic species on oxocarbenium ions in furanoside series is well documented, it remains not fully predictable. ${ }^{[5]}$ The stereochemical outcome of addition reactions on furanosyl oxocarbenium is dictated by stereoelectronic factors and highly dependent on the substrate structures. ${ }^{[6]}$ For polysubstituted substrates, the conformational stability and reactivity of oxocarbenium ion is controlled by the interplay between the ring substituents and their relative effects.

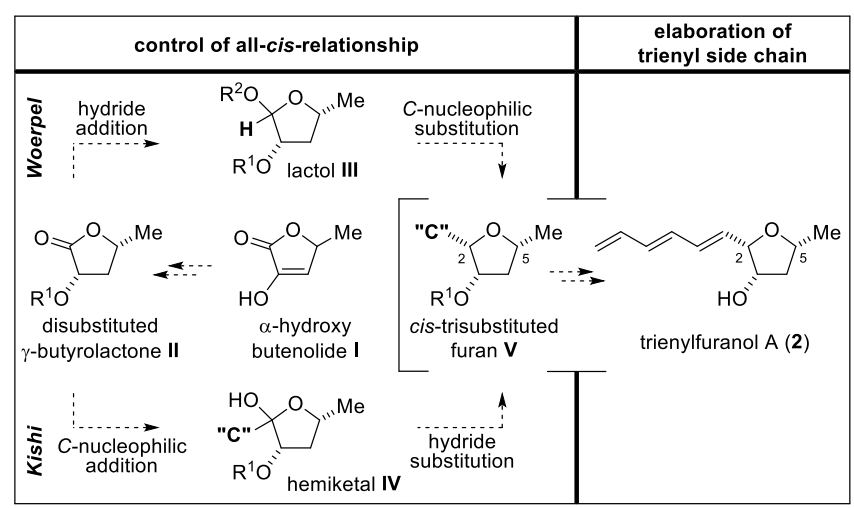

Scheme 1. Retrosynthetic pathway of trienylfuranol A (2).

Indeed, in contrast with six-membered ring cation series, a predictive stereochemical model of addition reactions on fivemembered ring oxocarbenium ions is not available. ${ }^{[7]}$ The stereoselectivity remains elusive, difficult to predict and occurred often with counterintuitive selectivity. As we are not able to anticipate the cumulative stereochemical effects of the 1,2- and 1,4-stereoinduction of the disubstituted $\gamma$-butyrolactone II, we have considered two approaches to introduce the functionalized side chain, precursor of the trienyl moiety. The first one is based on a well-established $C$-nucleophilic substitution on lactol III, 
which is obtained by hydride reduction of lactone II. This general approach has been studied by several groups with different nucleophiles and various Lewis acid. Woerpel and co-workers have proposed stereochemical models to account stereodirecting substituent effects on five- and six-membered ring oxocarbenium ions and to explain the stereoselective formation of $C$ furanosides ${ }^{[8]}$ and $C$-pyranosides ${ }^{[9]}$ series, respectively. The second approach, developed by Kishi and co-workers for the formation of $C$-glycopyranoside, consists of the same in a reverse sequence. ${ }^{[10]}$ First, $C$-nucleophile species was added on lactone type compound II to lead to hemiketal intermediate IV, which undergoes subsequent deoxygenation by treatment with hydrosilane and boron trifluoride etherate. This formation of $C$ glycoside was extended to furanoside series ${ }^{[11]}$ and commonly applied to the formation of $C$-nucleosides. ${ }^{[12]}$

We first prepared the disubstituted $\gamma$-butyrolactone 7 and its reduced $O$-acyl lactol 9 counterpart (Scheme 2). The synthesis of these compounds is based on previous reports ${ }^{[13]}$ where pyruvic acid 4 was condensed with acetaldehyde through a gram-scale acid-catalyzed aldol/crotonisation/lactonisation sequence to provide the $\alpha$-hydroxy- $\gamma$-butenolide $5 .^{[14]}$ This unsaturated lactone 5 was reduced under hydrogenation over $10 \% \mathrm{Pd} / \mathrm{C}$ in EtOAc to set up the hydroxyl function and methyl substituents in cis relative configuration via a 1,3-induced asymmetric hydrogenation. ${ }^{[15]}$ The disclosed secondary alcohol of $\mathbf{6}$ was protected as its TBS ether in $93 \%$ yield and the protected lactone 7 was reduced with DIBAL$\mathrm{H}$ to yield the lactol $\mathbf{8}$ and acetylated to provide the more stable $O$-acyl lactol 9 in good yields.

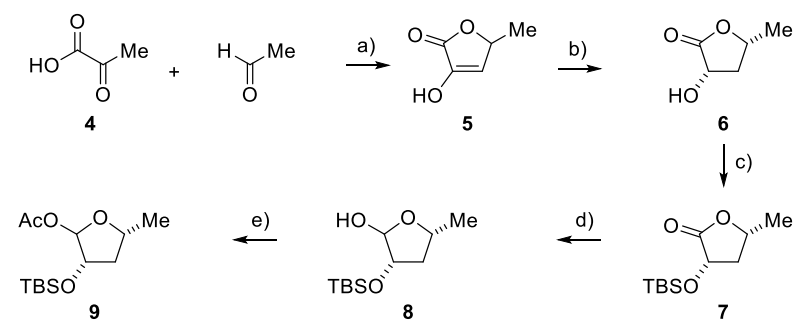

Scheme 2. Preparation of disubstituted $\gamma$-butyrolactone and their reduced lactol counterparts. Reagents and conditions: a) $\mathrm{H}_{2} \mathrm{SO}_{4}$ conc., $0^{\circ} \mathrm{C}$ to $\mathrm{RT}, 30 \mathrm{~min}$., $31 \%$. b) $\mathrm{H}_{2}, \mathrm{Pd} / \mathrm{C} 10 \%$, EtOAc, RT, $24 \mathrm{~h}, 70 \%$. c) TBSOTf, 2,6-di-tertbutylpyridine, $\mathrm{CH}_{2} \mathrm{Cl}_{2}, 0{ }^{\circ} \mathrm{C}$ to RT, $1.5 \mathrm{~h}, 93 \%$. d) DIBAL-H, $\mathrm{CH}_{2} \mathrm{Cl}_{2},-78{ }^{\circ} \mathrm{C}$ to $15^{\circ} \mathrm{C}, 2.5 \mathrm{~h}, 41 \%$. e) $\mathrm{Ac}_{2} \mathrm{O}$, DMAP cat., $\mathrm{CH}_{2} \mathrm{Cl}_{2}, 0{ }^{\circ} \mathrm{C}, 1.5 \mathrm{~h}, 85 \%$.

We started the synthesis of the targeted cis-trisubstituted furan $\mathbf{V}$ from the $O$-acetyl substrate 9 by a homologation reaction with allyltrimethylsilane as $C$-nucleophile in presence of Lewis acid. ${ }^{[16]}$ We have used $\mathrm{SnBr}_{4}$ as Lewis acid which is widely employed by Woerpel and co-workers for five-membered-ring oxocarbenium ions $^{[8 \mathrm{~B}]}$ and used recently by Ghosh and co-workers for the synthesis of amphirionin-4 ${ }^{[17]}$ and monocerin, ${ }^{[18]}$ while other Lewis acids such as $\mathrm{BF}_{3} . \mathrm{OEt}_{2}, \mathrm{TiCl}_{4}$ or $\mathrm{TMSOTf}$ are described as less efficient. In our hands, with these conditions, the nucleophilic substitution of $\mathrm{O}$-acetyl moiety of compound $\mathbf{9}$ with allyltrimethylsilane provided to the desired allylated compound $\mathbf{1 0}$ in good yield with an excellent $\alpha$-selective substitution as previously observed by Ghosh and co-workers (Scheme 3). ${ }^{[17]}$ The oxidative cleavage of the corresponding alkene function by ozonolysis leads to the aldehyde $\mathbf{1 1}$ in $75 \%$ yield. Aldehyde $\mathbf{1 1}$ was reacted with $(E)$-1-lithio-1,3-butadiene, generated from the corresponding tributylstannane derivative $\mathbf{1 2}^{[19]}$ by transmetallation, ${ }^{[19 a]}$ to form the $(E)$-butadienylated adduct $\mathbf{1 3}$ in an optimized yield of $62 \%$ yield and as a mixture of epimers in a 1:1 ratio. However, the dehydration of 1,3-butadienyl carbinol $\mathbf{1 3}$ into the targeted compound $\mathbf{1 4}$ with the trienic side chain was more difficult than expected. All attempts of direct dehydration of 13 or reactions involving the introduction of better leaving groups failed. We have only observed the consumption of starting material and extensive formation of decomposition products. This would suggest that elimination reaction conditions are not compatible with the unusual and very sensitive terminal trienyl moiety. ${ }^{[4]}$ We consequently designed an alternative mild synthetic pathway to preserve the trienyl moiety.

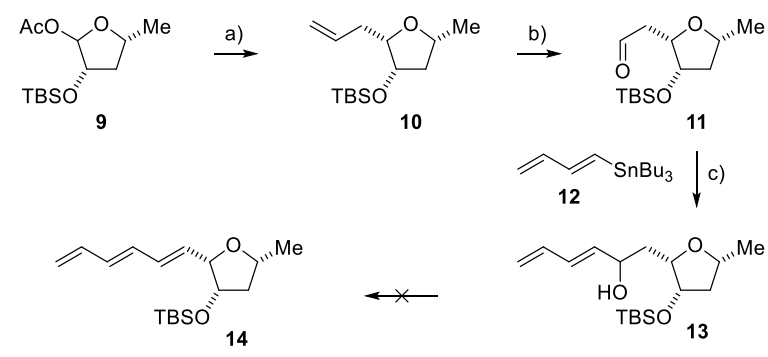

Scheme 3. Nucleophilic substitution with allyltrimethylsilane. Reagents and conditions: a) Allyltrimethylsilane, $\mathrm{SnBr}_{4}, \mathrm{CH}_{2} \mathrm{Cl}_{2}, \mathrm{RT}, 30$ min., $80 \%$. b) $\mathrm{O}_{3}$, $\mathrm{CH}_{2} \mathrm{Cl}_{2},-78^{\circ} \mathrm{C}, 5 \mathrm{~min}$. then $\mathrm{PPh}_{3},-78^{\circ} \mathrm{C}$ to RT $16 \mathrm{~h}, 75 \%$. c) (E)-Buta-1,3-dien1-yltributylstannane $12, n$-BuLi, THF, $-78^{\circ} \mathrm{C}$ to RT, $16 \mathrm{~h}, 62 \%$.

We turned out to an approach which implies the use of the same (E)-buta-1,3-dien-1-yltributylstannane 12 for the construction of the trienic unit, in milder conditions by Pd-catalyzed crosscoupling reactions. To achieve this objective, we plan to prepare a furan $\mathbf{V}$ bearing a functionalized vinyl unit. This partner for the targeted cross-coupling reaction could be obtained from an alkyne derivative. Thus, in place of allyltrimethylsilane for the nucleophilic substitution on $O$-acetyl compound 9, we have considered alkynyl species as $C$-nucleophile (Table 1 ). To realize this nucleophilic substitution, we intend to use organoalane reagents, successfully used for the introduction of the alkynyl groups at the anomeric position for nucleoside synthesis. ${ }^{[20]}$ In our case, the most suitable organoalane reagent is ethyl[trimethylsilyl(ethynyl)]aluminum chloride, prepared in situ by transmetallation of lithio-ethynyltrimethylsilane with ethylaluminum dichloride. An excess of this reagent was used to assist the departure of acetyl moiety on the one hand, and to perform the addition on the generated oxocarbenium on the other. ${ }^{[21]}$ The reaction of $O$-acyl compound 9 with the in situ prepared organoalane reagent furnished cleanly the alkynylated product in $66 \%$ yield. However, to our great surprise we have observed a highly $\beta$-selective reaction, in 95:5 C-2 epimeric mixture in favor of the $\beta$-isomer $\mathbf{1 6}$. The relative stereochemistry of this major $\beta$-isomer 16 and minor $\alpha$-isomer 15 were independently assigned on the basis of the 2D NOESY spectra. For the $\beta$-isomer 16, key NOE cross-peaks was observed between $\mathrm{H}-2$ and $\mathrm{CH}_{3}-5$ while the desired minor $\alpha$-isomer 15 display a correlation between $\mathrm{H}-2$ and $\mathrm{H}-5$ (see supporting information). Other conditions using indium-mediated alkynylation under Barbier conditions ${ }^{[22]}$ lead to the same outcome in terms of stereoselectity.

Table 1. Nucleophilic substitution of 9 with alkynyl species. 


\begin{tabular}{|c|c|c|c|c|c|}
\hline TBSO" & & & 15 & \multicolumn{2}{|c|}{ TBSO } \\
\hline Entry & Reagents & & Conditions & Yield ${ }^{[a]}$ & $15 / 16^{[b]}$ \\
\hline 1 & $\begin{array}{l}\text { Trimethyls } \\
n \text {-BuLi the }\end{array}$ & $\begin{array}{l}\text { etylene } \\
\mathrm{ICl}_{2}\end{array}$ & $\begin{array}{l}\text { Tol./ } / \mathrm{CH}_{2} \mathrm{Cl}_{2} 1: 1 \\
0^{\circ} \mathrm{C} \text { to } \mathrm{RT}, 18 \mathrm{~h}\end{array}$ & $66 \%$ & $5: 95$ \\
\hline 2 & $\begin{array}{l}\text { 1-lodo-2- } \mathrm{t} \\
\text { acetylene, }\end{array}$ & $\begin{array}{l}\text { hylsilyl)- } \\
\mathrm{m}^{(0)}\end{array}$ & $\mathrm{CH}_{2} \mathrm{Cl}_{2}$, reflux, $20 \mathrm{~h}$ & $59 \%$ & $5: 95$ \\
\hline
\end{tabular}

[a] Yield of isolated product. [b] Determined by ${ }^{1} \mathrm{H}$ NMR analysis of the crude reaction mixtures.

As the undesired $\beta$-isomer $\mathbf{1 6}$ was obtained during the previous Woerpel approach, we turned out to the complementary Kishi sequence which consists to introduce firstly the alkynyl moiety and to reduce the resulting hemiketal IV in the last step. ${ }^{[10]}$ The lactone $\mathbf{7}$ was treated with the in situ prepared lithium(trimethylsilyl)acetylide at $-45^{\circ} \mathrm{C}$ to $-25^{\circ} \mathrm{C}$ for two hours to provide the hemiketal $\mathbf{1 7}$, isolated as a crude product in $95 \%$ yield (Table 2). All the trials to purify hemiketal $\mathbf{1 7}$ induced a significant fall of material and gave lower quality NMR spectra. The following reductive-deoxygenation of the crude hemiketal $\mathbf{1 7}$ was initially performed by the classical triethylsilane as reducing agent with $\mathrm{BF}_{3} . \mathrm{Et}_{2} \mathrm{O}$ as promoter. Unfortunately, once again the undesired $\beta$ isomer 16 was produced (Table 2, entry 1 ). Other hydrosilanes as hydride sources or the use of tributyltin hydride also led to the same $\beta$-isomer 16 in lower yields (entry 2). With these disappointing results, we turned to the use of organic derivatives as reducing agent. First we have performed the reaction with Hantzsch ester $(\mathrm{HEH}),{ }^{[23]}$ a simplest $\mathrm{NAD}(\mathrm{P}) \mathrm{H}$ mimics widely used as reductant in the hydrogenation of unsaturated bonds and successfully used to trap in situ oxonium species. ${ }^{[2]}$ To our delight, even if the yield is low, the reaction with kemiketal $\mathbf{1 7}$ and $\mathrm{HEH}$ as a reducing agent for oxocarbenium reduction provided the desired $\alpha$-isomer 15 (entry 3). This diastereodivergence for triethylsilane and $\mathrm{HEH}$ was previously observed by MacMillan and co-workers during the synthesis of $C$-nucleoside compounds in ribose series. ${ }^{[25]}$ Taking into account the low stability of oxocarbenium intermediate and working at lower temperature, the desired $\alpha$ isomer $\mathbf{1 5}$ was isolated in $23 \%$ yield for two steps from lactone $\mathbf{7}$ (entry 4). The use of other synthetic $\mathrm{NAD}(\mathrm{P}) \mathrm{H}$ analogue like 9,10dihydrophenanthridine ${ }^{[26]}$ (entry 5) or benzothiazoline ${ }^{[27]}$ (entry 6) lead to a complex mixture of several compounds, where the desired reduced compounds $\mathbf{1 5}$ or $\mathbf{1 6}$ were not observed. Switching from Lewis to Brønsted acid to generate the oxocarbenium ion intermediate turned out to be detrimental for reactivity. The use of diphenylphosphate ${ }^{[28]}$ or more acidic promoters such as camphorsulfonic acid or triflimide did not lead to any reaction (entries 7-9). ${ }^{[29]}$

On large scale synthesis, small quantity of over-reduced compound 18 was observed and can be cleanly isolated. The hydrogenation of alkyne function to alkane derivatives with $\mathrm{HEH}$ as hydrogen donors was reported under palladium catalysis ${ }^{[30]}$ but, to the best of our knowledge, this result represents the first example of alkyne reduction with $\mathrm{HEH}$ under metal-free conditions.

Table 2. Introduction of alkynyl moiety using Kishi's protocol.

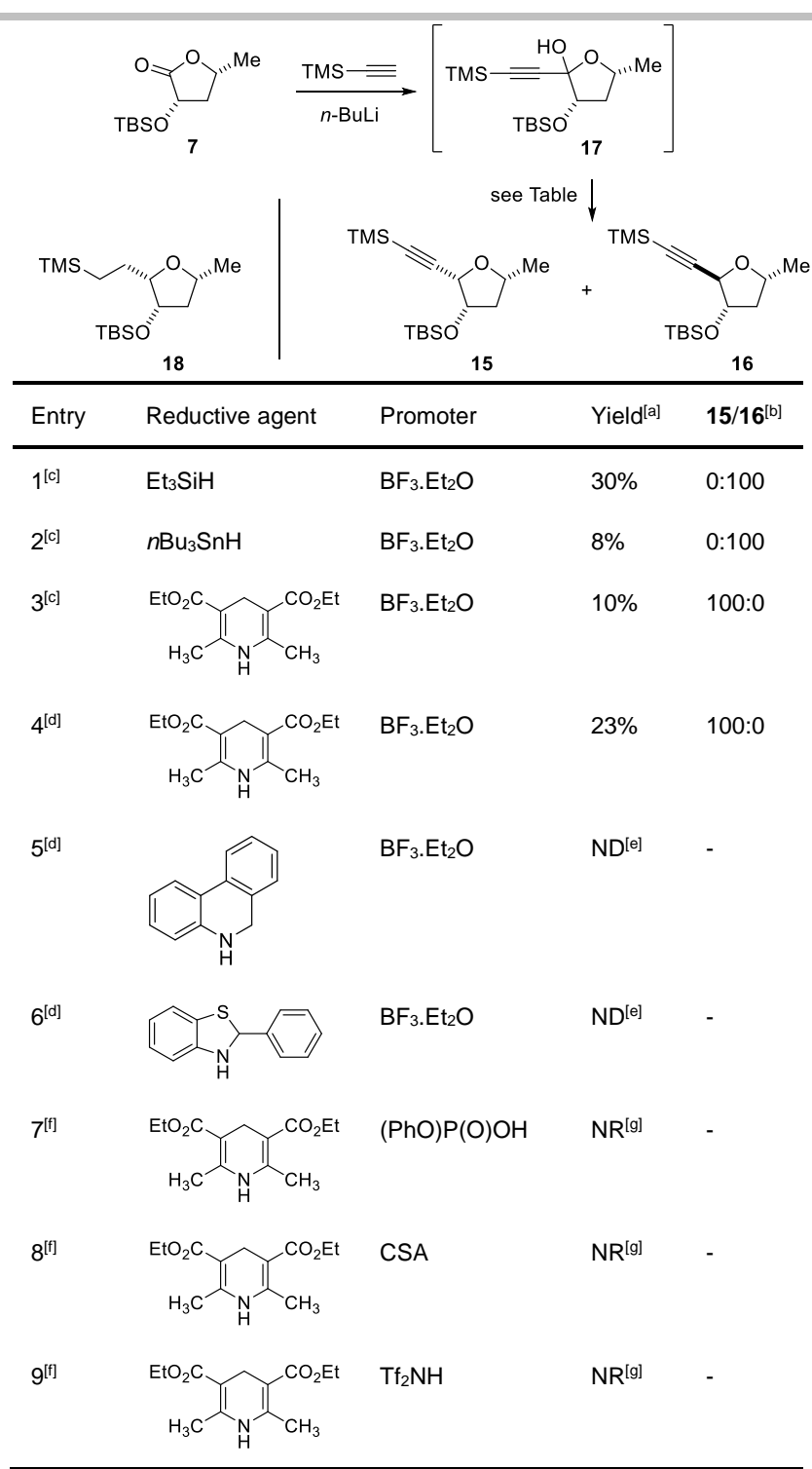

Reagents and conditions for the first step: Trimethylsilylacetylene, $n$-BuLi, $45^{\circ} \mathrm{C}$ to $-25^{\circ} \mathrm{C}, 2 \mathrm{~h}$., $95 \%$ (crude product). [a] Overall yield of isolated products for the two steps. [b] Determined by ${ }^{1} \mathrm{H}$ NMR analysis of the crude reaction mixtures. [c] Reductive agent (4 equiv), promoter (4 equiv), $\mathrm{CH}_{2} \mathrm{Cl}_{2},-40{ }^{\circ} \mathrm{C}, 2 \mathrm{~h}$. [d] Reductive agent (2.5 equiv), promoter (2.5 equiv), $\mathrm{CH}_{2} \mathrm{Cl}_{2},-60^{\circ} \mathrm{C}$ to $-40{ }^{\circ} \mathrm{C}$ 2 h. [e] ND=product 15 or 16 not detected. [f] Reductive agent (2 equiv), promoter (0.2 equiv), $4 \AA$ A molecular sieves, Toluene, RT, $16 \mathrm{~h}$ and $50^{\circ} \mathrm{C}, 6 \mathrm{~h}$. [g] NR=no reaction.

As the nature and configuration of functional groups on furan ring determines the stability and reactivity of oxocarbenium ions intermediate, but also the conformation of the formed product, we decided to assign unambiguously the relative stereochemistry by $X$-ray crystallography. The silyl protecting groups of $\mathbf{1 5}$ were removed by TBAF treatment to give the corresponding deprotected compound 19 (Scheme 4). The free secondary alcohol was derivatized into p-bromobenzoyl ester 20 and recrystallization of this solid compound from slow evaporation of its solution in methanol yielded single crystals suitable for X-ray crystallography. The crystallographic analysis showing an all-cis orientation of the substituents on the furan ring and confirming the relative stereochemistry assignment deduced from NOE correlations (Figure 2). ${ }^{[31]}$ 


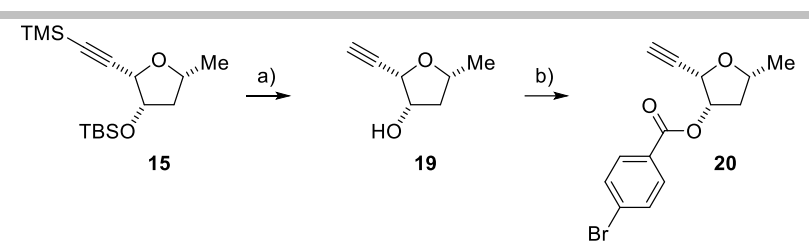

Scheme 4. Derivatisation of $\alpha$-isomer 15 as its para-bromobenzoate 20 Reagents and conditions: a) TBAF, THF, RT, 2 h., $28 \%$. b) para-bromobenzoic acid, DCC, DMAP, $\mathrm{CH}_{2} \mathrm{Cl}_{2}, 0^{\circ} \mathrm{C}$ to $\mathrm{RT}, 18 \mathrm{~h}, 45 \%$.

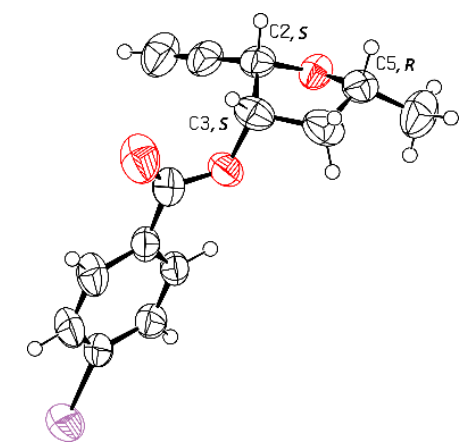

Figure 2. X-ray crystal structure of 20 .

After carrying out the synthesis of desired functionalized furan 15, the last stage to complete the synthesis of trienylfuranol $A$ involve the introduction of the trienyl side chain. For this purpose, the TMS group of $\mathbf{1 5}$ was selectively removed by treatment with methanol under basic conditions to afford the terminal alkyne 21, which was converted into (E)-vinyl iodide 22 by a hydrozirconation-iodination sequence with Schwartz reagent ${ }^{[32]}$ prepared in situ from $\mathrm{Cp}_{2} \mathrm{ZrCl}_{2}$ and DIBAL- $\mathrm{H}^{[33]}$ and then followed by iodine treatment (Scheme 5). A Stille cross-coupling reaction ${ }^{[34]}$ between vinyl iodide 22 and the previously prepared dienylstannane $\mathbf{1 2}^{[19]}$ proceed under mild conditions at room temperature to afford the expected terminal triene $\mathbf{1 4}$ in satisfactory $71 \%$ yield. Subsequent desilylation of TBS protecting group with TBAF produced the targeted trienylfuranol A (2).

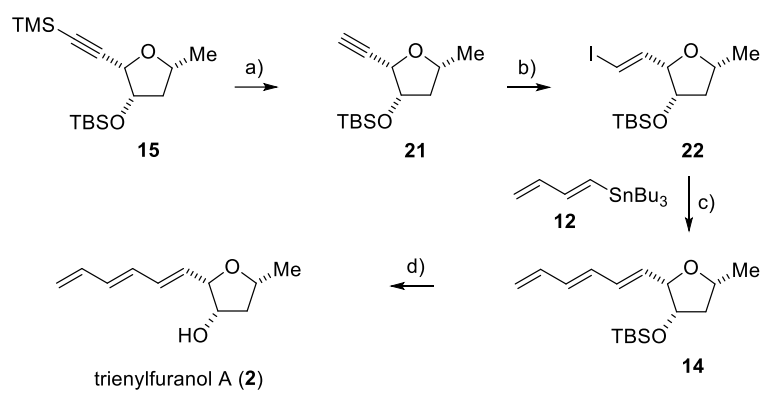

Scheme 5. Completion of the total synthesis of trienylfuranol A (2). Reagents and conditions: a) $\mathrm{K}_{2} \mathrm{CO}_{3}, \mathrm{MeOH}, \mathrm{RT}, 3 \mathrm{~h}$., $63 \%$. b) $\mathrm{Cp}_{2} \mathrm{ZrCl}_{2}$, DIBAL-H, $0{ }^{\circ} \mathrm{C}$ to $\mathrm{RT}, 50$ min., then $\mathrm{l}_{2},-78{ }^{\circ} \mathrm{C}$ to RT 2 h., 63\%. c) (E)-Buta-1,3-dien-1yltributylstannane 12, $\mathrm{PdCl}_{2}\left(\mathrm{CH}_{3} \mathrm{CN}\right)_{2}, \mathrm{RT}, 3$ h., $71 \%$. d) TBAF, THF, $0^{\circ} \mathrm{C}$ to $\mathrm{RT}$, 3 h., $43 \%$.

In order to identify the natural isomer of trienylfuranol A $\mathbf{2}$ in this racemic mixture, the two enantiomers were separated by Supercritical Fluid Chromatography (SFC) on a semi-preparative chiral column, and their $[\alpha]_{\mathrm{D}}^{20}$ measured (see supporting information). Among the two chromatographic peaks, the natural isomer has a retention time of $5.6 \mathrm{~min}$ and a specific optical rotation $[\alpha]_{\mathrm{D}}^{20}+1.7\left(c=0.10, \mathrm{CH}_{3} \mathrm{CN}\right)$ [reported $+1.9(c=1.10$, $\left.\mathrm{CH}_{3} \mathrm{CN}\right)$ ]. The unnatural antipode, with a retention time of 12.3 min, gives an opposite optical rotation $[\alpha]_{\mathrm{D}}^{20}=-2.0 \quad(c=0.10$, $\mathrm{CH}_{3} \mathrm{CN}$ ).

In conclusion, the first total synthesis of trienylfuranol $\mathrm{A}$ was achieved in 8 steps, from acetaldehyde and pyruvic acid. The synthetic route was adapted to provide a concise and efficient approach for the synthesis of this natural metabolite taking into account of the very sensitive terminal trienyl moiety. Moreover, we have developed a diastereodivergent approach for the stereogenic center bearing this trienic side chain. Starting from $\gamma$ lactone as substrate, the addition reactions of alkyne nucleophilic species and hydride reagent on the carbonyl moiety allow access, with high selectively, both cis and trans diastereoisomers, which are unambiguously assigned by $\mathrm{X}$-ray studies. The ordering of the reaction sequence but also and above an appropriate choice of the reducing agent allow to ensure the stereocontrol. A separation by Supercritical Fluid Chromatography on chiral stationary phase allow the obtaining and characterization of the enantiomerically natural pure $(+)$-antipode. While we recently contributed to the elucidation of the biosynthesis pathway of the sporothriolide $1,{ }^{[35]}$ the biosynthesis of the trienylfuranol A 2 and sporochartines 3 remains to be elucidated, in particular the involvement of a DielsAlder type reaction. We will benefit from the availability of the synthetized trienylfuranol $A$ and sporothriolide to engage chemoenzymatic reactions and establish unambigously the sporochartines formation pathway. This work is ongoing in our laboratory.

\section{Acknowledgements}

SFC separation of compound 2 enantiomers was performed by the HPLC platform of ICSN, CNRS, Gif-sur-Yvette, France. The authors are grateful to Nathalie Hue and Vincent Steinmetz.

Keywords: Natural products • Total synthesis • Diastereoselectivity $\cdot$ Hydrides $\bullet$ Reduction

[1] a) C. Leman-Loubière, G. Le Goff, P. Retailleau, C. Debitus, J. Ouazzani, J. Nat. Prod. 2017, 80, 2850-2854; b) C. LemanLoubière, G. Le Goff, C. Debitus, J. Ouazzani, Front. Mar. Sci. 2017, 4, Article 399.

[2] D. Wibberg, M. Stadler, C. Lambert, B. Bunk, C. Spröer, C. Rückert, J. Kalinowski, R. J. Cox, E. Kuhnert, Fungal Divers. 2020 10.1007/s13225-13020-00447-13225.

[3] a) K. Krohn, K. Ludewig, H. J. Aust, S. Draeger, B. Schulz, J. Antibiot. 1994, 47, 113-118; b) L.-L. Cao, Y.-Y. Zhang, Y.-J. Liu, T.-T. Yang, J.-L. Zhang, Z.-G. Zhang, L. Shen, J.-Y. Liu, Y.-H. Ye, Pestic. Biochem. Physiol. 2016, 129, 7-13. Antibiot 2017, 70,721-725.

[5] Y. Yang, B. Yu, Chem. Rev. 2017, 117, 12281-12356.

[6] E. R. van Rijssel, P. van Delft, G. Lodder, H. S. Overkleeft, G. A van der Marel, D. V. Filippov, J. D. C. Codee, Angew. Chem. Int Ed. 2014, 53, 10381-10385.

[7] D. M. Smith, K. A. Woerpel, Org. Biomol. Chem. 2006, 4, 11951201.

[8] a) C. H. Larsen, B. H. Ridgway, J. T. Shaw, K. A. Woerpel, J. Am. Chem. Soc. 1999, 121, 12208-12209; b) C. H. Larsen, B. H. Ridgway, J. T. Shaw, D. M. Smith, K. A. Woerpel, J. Am. Chem. Soc. 2005, 127, 10879-10884

[9] a) J. A. C. Romero, S. A. Tabacco, K. A. Woerpel, J. Am. Chem. Soc. 2000, 122, 168-169; b) L. Ayala, C. G. Lucero, J. A. C. Romero, S. A. Tabacco, K. A. Woerpel, J. Am. Chem. Soc. 2003, 125, 15521-15528.

[10] M. D. Lewis, J. K. Cha, Y. Kishi, J. Am. Chem. Soc. 1982, 104 4976-4978. 
[11] D. J. O'Leary, Y. Kishi, J. Org. Chem. 1994, 59, 6629-6636.

[12] K. Temburnikar, K. L. Seley-Radtke, Beilstein J. Org. Chem. 2018 14, 772-785.

[13] D. I. MaGee, T. C. Mallais, P. D. M. Mayo, G. M. Strunz, Tetrahedron 2006, 62, 4153-4161.

[14] H.-Y. Kang, Y.-M. Ji, Y.-K. Yu, Y. Lee, S.-J. Lee, Bull. Korean Chem. Soc. 2003, 24, 1819-1826.

[15] S. A. M. T. Hussain, W. D. Ollis, C. Smith, J. F. Stoddart, J. Chem. Soc., Perkin Trans. 11975, 1480-1492.

[16] A. P. Kozikowski, K. L. Sorgi, Tetrahedron Lett. 1982, 23, 22812284.

[17] a) A. K. Ghosh, P. R. Nyalapatla, Org. Lett. 2016, 18, 2296-2299; b) A. K. Ghosh, P. R. Nyalapatla, Tetrahedron 2017, 73, 18201830.

[18] A. K. Ghosh, D. S. Lee, J. Org. Chem. 2019, 84, 6191-6198

[19] a) P. A. Wender, S. M. Sieburth, J. J. Petraitis, S. K. Singh, Tetrahedron 1981, 37, 3967-3975; b) A. M. Gómez, J. C. López, B. Fraser-Reid, Synthesis 1993, 943-944.

[20] Y. Itoh, K. Haraguchi, H. Tanaka, E. Gen, T. Miyasaka, J. Org Chem. 1995, 60, 656-662.

[21] K. Haraguchi, M. Sumino, H. Tanaka, J. Org. Chem. 2006, 71 4433-4438.

[22] N. Lubin-Germain, J.-P. Baltaze, A. Coste, A. Hallonet, H. Lauréano, G. Legrave, J. Uziel, J. Augé, Org. Lett. 2008, 10, 725 728.

[23] a) Y. J. Huang, Synlett 2007, 2304-2305; b) C. Zheng, S.-L. You, Chem. Soc. Rev. 2012, 41, 2498-2518.

[24] a) K. Saito, Y. Kajiwara, T. Akiyama, Angew. Chem. Int. Ed. 2013, 52, 13284-13288; b) M. Terada, F. Li, Y. Toda, Angew. Chem. Int. Ed. 2014, 53, 235-239.

[25] M. Peifer, R. Berger, V. W. Shurtleff, J. C. Conrad, D. W. C. MacMillan, J. Am. Chem. Soc. 2014, 136, 5900-5903.

[26] Q.-A. Chen, K. Gao, Y. Duan, Z.-S. Ye, L. Shi, Y. Yang, Y.-G. Q.-A. Chen, K. Gao, Y. Duan, Z.-S. Ye, L. Shi, Y. Ya
Zhou, J. Am. Chem. Soc. 2012, 134, 2442-2448.

[27] a) H. Chikashita, M. Miyazaki, K. Itoh, Synthesis 1984, 308-310; b) c. Zhu, T. Akiyama, Org. Lett. 2009, 11, 4180-4183.

[28] a) R. Lu, Y. Li, J. Zhao, J. Li, S. Wang, L. Liu, Chem. Comm. 2018 54, 4445-4448; b) M. Wan, S. Sun, Y. Li, L. Liu, Angew. Chem. Int. Ed. 2017, 56, 5116-5120.

[29] C. Ko, J. B. Feltenberger, S. K. Ghosh, R. P. Hsung, Org. Lett. 2008, 10, 1971-1974.

[30] Y. Zhao, Q. Liu, J. Li, Z. Liu, B. Zhou, Synlett 2010, 1870-1872.

[31] Crystallographic data for the compound 20 have been deposited at the CCDC, Cambridge, UK, with the deposit number 2052218. The supplementary crystallographic data can be obtained free of charge from The Cambridge Crystallographic Data Centre via URL www.ccdc.cam.ac.uk/data request/cif.

[32] D. W. Hart, J. Schwartz, J. Am. Chem. Soc. 1974, 96, 8115-8116.

[33] Z. Huang, E.-i. Negishi, Org. Lett. 2006, 8, 3675-3678.

[34] P. Espinet, A. M. Echavarren, Angew. Chem. Int. Ed. 2004, 43, 4704-4734.

[35] D.-S. Tian, E. Kuhnert, J. Ouazzani, D. Wibberg, J. Kalinowski, R. J. Cox, Chem. Sci. 2020, 11, 12477-12484. 